\title{
Effects of reducing processed culinary ingredients and ultra-processed foods in the Brazilian diet: a cardiovascular modelling study
}

\author{
Patrícia VL Moreira ${ }^{1,2, *}$, Lirije Hyseni ${ }^{1}$, Jean-Claude Moubarac ${ }^{3}$, Ana Paula B Martins ${ }^{3}$, \\ Larissa G Baraldi ${ }^{3}$, Simon Capewell ${ }^{1}$, Martin O'Flaherty ${ }^{1}$ and Maria Guzman-Castillo' \\ 'Department of Public Health, University of Liverpool, Whelan Building, Quadrangle, Liverpool L69 3GB, UK: \\ ${ }^{2}$ Department of Nutrition, Federal University of Paraíba, João Pessoa, Brazil: ${ }^{3}$ Centre for Epidemiological \\ Studies in Health and Nutrition, Public Health Faculty, University of São Paulo, São Paulo, Brazil
}

Submitted 13 October 2016: Final revision received 13 June 2017: Accepted 19 June 2017: First published online 8 September 2017

\begin{abstract}
Objective: To estimate the impact of reducing saturated fat, trans-fat, salt and added sugar from processed culinary ingredients and ultra-processed foods in the Brazilian diet on preventing cardiovascular deaths by 2030.

Design: A modelling study.

Setting: Data were obtained from the Brazilian Household Budget Survey 2008/2009. All food items purchased were categorized into food groups according to the NOVA classification. We estimated the energy and nutrient profile of foods then used the IMPACT Food Policy model to estimate the reduction in deaths from CVD up to 2030 in three scenarios. In Scenario A, we assumed that the intakes of saturated fat, trans-fat, salt and added sugar from ultra-processed foods and processed culinary ingredients were reduced by a quarter. In Scenario B, we assumed a reduction of $50 \%$ of the same nutrients in ultra-processed foods and processed culinary ingredients. In Scenario C, we reduced the same nutrients in ultra-processed foods by $75 \%$ and in processed culinary ingredients by $50 \%$.

Results: Approximately 390400 CVD deaths might be expected in 2030 if current mortality patterns persist. Under Scenarios A, B and C, CVD mortality can be reduced by $5 \cdot 5,11.0$ and $29.0 \%$, respectively. The main impact is on stroke with a reduction of approximately $6 \cdot 0,12 \cdot 6$ and $32 \cdot 0 \%$, respectively.

Conclusions: Substantial potential exists for reducing the CVD burden through overall improvements of the Brazilian diet. This might require reducing the penetration of ultra-processed foods by means of regulatory policies, as well as improving the access to and promotion of fresh and minimally processed foods.
\end{abstract}

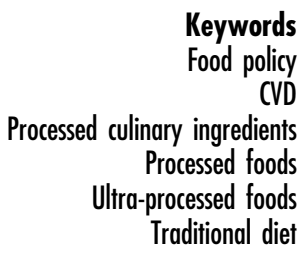

Keywords

policy

ients processed foods Traditional diet
Over 35 million people die annually from noncommunicable diseases, with the majority of this burden coming from $\mathrm{CVD}^{(1,2)}$. Four major risk factors generate non-communicable diseases: poor diet, alcohol, tobacco and physical inactivity, with poor diet generating more noncommunicable diseases than the other three risk factors combined $^{(3)}$. Consumption of ultra-processed food (UPF) products negatively impacts the nutritional quality of diets as these UPF are nutritionally imbalanced compared with non-UPF ${ }^{(4-9)}$. UPF are energy-dense and typically high in saturated fat, trans-fat, sodium and added sugar ${ }^{(4,10)}$.

Monteiro et al. $^{(11)}$ compared the consumption of UPF in high- and middle-income countries, specifically Canada and Brazil, and found that the total amount of energy purchased as UPF was almost twice high in Canada (from a survey in 2001) compared with Brazil (from a survey in 2003).
Similar patterns were observed when comparing Brazil with the UK and USA: ready-to-consume products, which include both processed foods and UPF, accounted for $63 \%$ of energy purchased in the UK in 2008, compared with $28 \%$ in Brazil between 2008 and $2009^{(12)}$. In the USA, UPF accounted for approximately $58 \%$ of the total energy purchased for 2009-2010(5). Despite Brazil consuming less energy from UPF compared with high-income countries, the consumption of UPF in this country is increasing at a more rapid rate: Monteiro et al. ${ }^{(11)}$ reported that the annual growth of UPF in Brazil ( $2 \cdot 1 \%$ per year) is almost twice the annual growth in Canada ( $1.3 \%$ per year).

The current trend of increased consumption of UPF in Brazil is most likely related to the penetration of transnational food companies and the subsequent displacement of the traditional food system ${ }^{(13)}$. 
Overall, the energy share of UPF in Brazil is increasing in all economic strata; however, the largest increase is observed in those groups with lower incomes ${ }^{(14)}$. This is noteworthy, as some studies in Brazil show that the burden of obesity, for example, is higher among individuals in lower income groups $^{(15,16)}$ and that there is a relationship between obesity and household availability of processed foods and $\mathrm{UPF}^{(17)}$.

Furthermore, high consumption of added sugar ${ }^{(18-21)}$, sodium $^{(22,23)}$, saturated fat ${ }^{(24)}$ and trans-fat ${ }^{(25)}$ has been associated in the past with the development of CVD $^{(13,19,22)}$. These associations suggest that a diet high in UPF and therefore high in these nutrients is linked to CVD.

However, in Brazil, there is currently a lack of literature quantifying the links between consumption of UPF and the development of CVD. Modelling studies have shown it is possible to reduce or prevent CVD through changes in these risk factors ${ }^{(24,26-29)}$. The present paper therefore estimates the impact of reducing saturated fat, trans-fat, salt and added sugar from processed culinary ingredients and UPF in the Brazilian diet on preventing cardiovascular deaths by 2030 .

\section{Methods}

\section{Estimating the nutrient content of the Brazilian diet from bousebold survey data}

Data used in the model were obtained from the 2008/2009 Brazilian Household Budget Survey (HBS) $)^{(30)}$ conducted by the Brazilian Institute of Geography and Statistics. The total number of households was approximately 56000 and the foods purchased by the household were recorded by the interviewer during seven consecutive days. Foods purchased for consumption away from home were not registered in detail (only the description of the type and value of the expense are available) and they were not included in the present study ${ }^{(30)}$.

All foods purchased were classified into groups according to the nature, extent and purpose of food processing. Essentially, foods were divided into four main groups according to the NOVA food classification ${ }^{(31)}$ : Group 1 (G1), unprocessed or minimally processed foods (fresh vegetables and fruits; grains; roots; tubers and others); Group 2 (G2), processed culinary ingredients (oils, fats, salt and sugar); Group 3 (G3), processed foods (canned or bottled vegetables and legumes (pulses) preserved in brine; un-reconstituted processed meat and fish such as ham, bacon, smoked fish; cheese; and others); and Group 4 (G4), ultra-processed food and drink products (chips, many types of sweets, fatty or salty snack products; ice cream, chocolates, candies (confectionery); burgers and hot dogs; poultry and fish 'nuggets' or 'sticks' ('fingers'); breads, buns, cookies (biscuits); breakfast cereals; and others). More detailed information on methodological classification can be found elsewhere ${ }^{(17,31,32)}$.

To quantify the amounts of energy, saturated fat, salt and added sugar of each food item purchased, we used the Brazilian Food Composition Table (TACO) ${ }^{(33)}$; or, if necessary, when the food item was not found in TACO, the US National Nutrient Database for Standard Reference was used ${ }^{(34)}$. Information on trans-fats was not available in the HBS. Therefore, to estimate trans-fat intake, we used data provided from another survey by the Brazilian Institute of Geography and Statistics looking at food consumption in a sub-sample of the HBS ( $25 \%$ of the HBS households) ${ }^{(35,36)}$.

It was assumed for the purposes of this model that foods in G1, G2 and G3 contain zero trans-fats. Only foods in G4 were ascribed trans-fat values according to the Brazilian Institute of Geography and Statistics ${ }^{(35)}$.

The HBS does not have age-specific data; therefore we used the same age distribution as in the $\mathrm{UK}^{(32)}$. Using the energy and nutrient intakes of 10-year age groups reported in the UK, we calculated the ratios between the quantities consumed in each age group and a base age group defined as 45-54 years. For example, in the UK, the group aged $\geq 75$ years consumes almost 1.4 times more added sugar than the group aged $45-54$ years. We applied these ratios to the Brazilian data, assuming that the amounts of energy and nutrients from food purchases reported by HBS were consumed by the base age group of 45-54 years.

\section{Modelling the effect of changing saturated fat, trans-fat, added sugar and salt consumption patterns}

We used the IMPACT Food Policy methodology ${ }^{(20,32,37)}$ to estimate potential CVD mortality reduction if saturated fat, trans-fat, salt and added sugar from processed culinary ingredients and UPF were reduced in the Brazilian diet.

Our primary outcome measure was the total number of deaths prevented or postponed (DPP) that can be attributed to the reduction of saturated fat, trans-fat, salt and added sugar in processed culinary ingredients and UPF. DPP are defined as the difference between the number of expected deaths in 2030 (age- and sex-specific CVD mortality rates in 2010 remained unchanged) and the expected deaths if saturated fat, trans-fat, salt and added sugar in processed culinary ingredients and UPF are reduced in the Brazilian diet.

The starting point for the model was to calculate the expected number of CHD and stroke deaths in 2030 by multiplying the age- and sex-specific mortality rates from CHD and stroke in 2010 by the population projections for 2030 in that age-sex stratum. Summing over all strata then yielded the expected number of deaths in 2030 had mortality rates remained unchanged. Population counts, CHD and stroke mortality rates, and observed numbers of deaths used in the model, along with sources, are listed in the online supplementary material.

To calculate DPP from changes in saturated fat, transfat, salt and added sugar, we used a regression approach, where the number of expected number of CHD deaths in 
2030 were multiplied by one minus the absolute change in the nutrient level (absolute difference in the nutrient levels between 2010 and 2030) multiplied by a regression coefficient $(\beta)$ quantifying the estimated relative change in CHD mortality that would result from a one-unit change in nutrient level. Stroke DPP were calculated likewise.

Nutrient mean levels and $\beta$ coefficients (meta-analyses of large cohort studies), along with their sources, are presented in the online supplementary material.

Changes in CVD mortality could be the result of simultaneous change in nutrient levels. Hence, part of the effect of one nutrient may be mediated through another. In this regard, we simultaneously estimated the effects of multiple nutrient changes on CVD mortality (more details in the online supplementary material).

We designed three scenarios to model the effect of decreasing saturated fat, trans-fat, salt and added sugar consumption:

1. In Scenario A (modest), we assumed that the intakes of saturated fat, trans-fat, salt and added sugar from G4 (UPF) would be reduced by $25 \%$, substituting this reduction in consumption with a $25 \%$ increase in the consumption of $\mathrm{G} 1$ (unprocessed or minimally processed foods). Additionally, we modelled a reduction of $25 \%$ in G2 (processed culinary ingredients) consumption.

2. In Scenario B (ideal), we assumed a reduction of $50 \%$ in saturated fats, trans-fat, salt and added sugar in G4 (UPF), substituting this reduction in consumption with a $50 \%$ increase in the consumption of G1 (unprocessed or minimally processed foods). Additionally, we modelled a reduction of $50 \%$ in G2 (processed culinary ingredients) consumption.

3. In Scenario C (optimistic), we reduced the intakes of saturated fat, trans-fat, salt and added sugar in G4 (UPF) by $75 \%$, substituting this reduction in consumption with a $75 \%$ increase in the consumption of G1 (unprocessed or minimally processed foods). Additionally, we modelled a reduction of $50 \%$ in G2 (processed culinary ingredients) consumption.

\section{Sensitivity analysis}

Finally, we implemented sensitivity analysis using the Excel add-in Ersatz software, which allows Monte Carlo simulation. This allows us to calculate $95 \%$ uncertainty intervals (95\% UI) for all model outputs, based on 5000 draws from specified probabilistic distributions for the model input variables. The parameter distributions used for the input variables to the DPP calculations are shown in the online supplementary material.

\section{Results}

\section{Nutrient levels in different food groups}

According to data from the HBS 2008/2009, the daily intake of energy among the population (estimated from purchased foods) is approximately $6700 \mathrm{~kJ}$ ( $1600 \mathrm{kcal})$. Added sugar and saturated fats account for 16 and $8 \%$ of this total, respectively (Table 1). Figure 1 shows the distribution of saturated fat, trans-fat and added sugar for each of the food groups.

The estimated daily intake of salt, based on quantity of sodium in food purchases, was $10 \mathrm{~g} / \mathrm{d}$, with most of the salt coming from G2 $(6.74 \mathrm{~g} / \mathrm{d})$ and G4 $(2.17 \mathrm{~g} / \mathrm{d})$, while substantially less came from G1 and G3 $(0.43$ and $0.55 \mathrm{~g} / \mathrm{d}$, respectively).

\section{Expected mortality reduction}

\section{Baseline}

In 2010, approximately 199000 CVD deaths were reported in Brazil. If 2010 age-specific rates persist unchanged, approximately 390400 CVD deaths might be expected in 2030 .

\section{Scenarios}

The results of DPP from CVD, CHD and stroke in Scenarios A, B and C are shown in Fig. 2.

In the modest scenario (Scenario A), where the intakes of saturated fat, trans-fat, salt and added sugar in G4 are reduced by $25 \%$, that energy is substituted for G1 energy and also where the same nutrients in G2 are reduced by the same proportion, it could lead to approximately 21100 (95\% CI 17 600, 25 300) fewer CVD-related deaths in 2030. This represents a $5.5 \%$ reduction in CVD mortality and denotes approximately 9430 (95\% CI 7400, 11 500) fewer CHD deaths and some 11670 (95\% CI 9300, 14900) fewer stroke deaths.

In the ideal and feasible scenario (Scenario B), where the current intakes of saturated fat, trans-fat, salt and added sugar are halved in G4, that energy is substituted for G1 and where also the same nutrients are halved in G2, it could lead to approximately 44190 (95\% CI 37570 , 51240 ) fewer CVD-related deaths in 2030. This would

Table 1 Average daily dietary energy, added sugar and saturated fat intakes of Brazilian households, estimated from foods purchased in the 2008/2009 Brazilian Household Budget Survey

\begin{tabular}{lcccccc}
\hline & Dietary energy & $95 \% \mathrm{Cl}$ & Added sugar & $95 \% \mathrm{Cl}$ & Saturated fat & $95 \% \mathrm{Cl}$ \\
\hline Average intake $\left(\mathrm{kcal}^{*}\right)$ & $1600 \cdot 0$ & $1556 \cdot 0,1664 \cdot 0$ & 256.0 & $250 \cdot 2,261.8$ & 132.2 & $129 \cdot 3,135 \cdot 0$ \\
Percentage of total energy & - & - & 16.0 & $15 \cdot 6,16.4$ & 8.3 & $8.1,8.4$ \\
Average intake $(\mathrm{g})$ & - & - & 63.9 & $61.3,66.5$ & 14.4 & $13.9,14.9$ \\
\hline
\end{tabular}

*To convert to kJ, multiply kcal value by $4 \cdot 184$. 


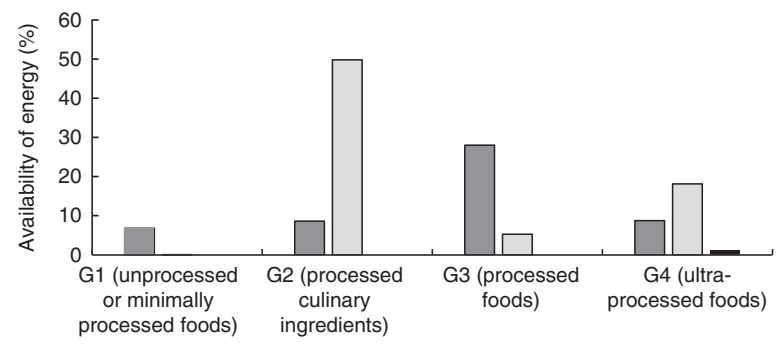

Fig. 1 Distribution (\%) of the availability of energy from saturated fat $(\square)$, added sugar $(\square)$ and trans-fat $(\square)$ in Brazilian households by NOVA classification group, estimated from foods purchased in the 2008/2009 Brazilian Household Budget Survey

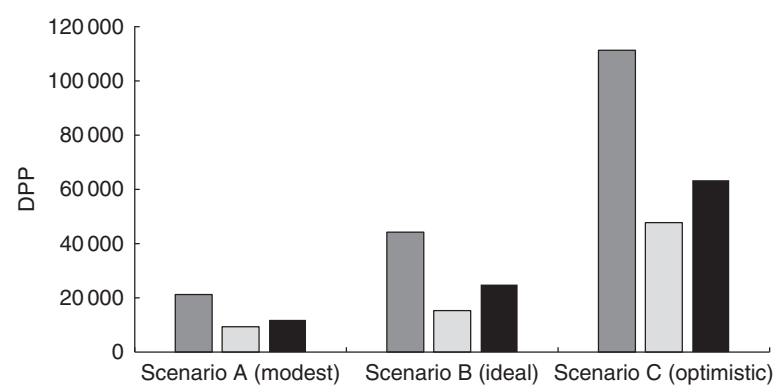

Fig. 2 Deaths prevented and postponed (DPP) by 2030 from CVD ( $\square$ ), CHD ( $\square$ ) and stroke ( $\square$ ) in the Brazilian population under Scenarios A, B and C that reduce intakes of saturated fat, trans-fat, salt and added sugar from ultra-processed foods and processed culinary ingredients

represent an $11 \%$ reduction in CVD mortality and denotes approximately 19340 (95\% CI 15310, 23 410) fewer CHD deaths and some 24850 (95\% CI 19790, 30250) fewer stroke deaths.

In the optimistic scenario (Scenario C), where the current intakes of saturated fat, trans-fat, salt and added sugar are reduced by $75 \%$ in G4, that energy is substituted for G1 and where the same nutrients are halved in G2, it could lead to approximately 111140 (95\% CI 68400, 160300) fewer CVD-related deaths in 2030. This would represent a $29 \%$ reduction in CVD mortality and denotes approximately 47740 (95\% CI 30 400, 60 300) fewer CHD deaths and some 63400 (95\% CI 31040, 99440) fewer stroke deaths.

The results for all scenarios by sex with cumulative effects are shown in Table 2.

\section{Discussion}

We quantified the number of deaths from CHD and stroke that might be prevented or postponed by reducing the consumption of saturated fat, trans-fat, salt and added sugar in processed culinary ingredients and UPF in Brazil.

The findings suggest that by 2030, approximately 44190 fewer CVD deaths ( $11 \%$ mortality reduction) could be achieved under an ideal scenario where the intake of UPF is reduced by $50 \%$ and substituted by a proportional increase of unprocessed or minimally processed foods, plus an additional $50 \%$ reduction of the processed culinary ingredients.

Intake reductions of 25 and $75 \%$ in UPF (the energy from which is proportionally replaced by unprocessed or minimally processed foods) and processed culinary ingredients could prevent or postpone approximately 21100 (5.5\% mortality reduction) and 111140 (29\% mortality reduction) CVD deaths, respectively.

The scenarios were constructed starting from a $25 \%$ reduction (modest scenario) of saturated fat, trans-fat, salt and added sugar in measures that are easier to achieve by the population. As we increase to 50 and $75 \%$ of substitution, we know they are targets that are harder to reach, but they are not impossible. This would gradually replace the energy from UPF to minimally processed foods.

The optimistic scenario (G4 and G2 reduced by 75 and $50 \%$, respectively) was proposed to specifically examine the potential effects on CVD mortality if Brazil would meet the international and national targets set for salt $(5 \mathrm{~g} / \mathrm{d})$ and sugar ( $10 \%$ of daily energy intake). The other two scenarios were proposed as intermediate stops in the journey to meet the targets.

Our model predicts bigger mortality reductions for stroke than for CHD if we reduce the consumption of UPF and processed culinary ingredients. These types of foods are very high in salt content (see Table 2); salt mediates the risk of CVD through its effect on blood pressure. A meta-analysis of one million adults in sixty-one prospective studies reported that high blood pressure has a higher effect on stroke mortality than in CHD mortality for adults younger than 70 years ${ }^{(38)}$. Therefore, a reduction of foods from G4 and especially G2 will have higher mortality reduction in stroke than in CVD for a young population such as the Brazilians.

\section{Comparison with other modelling studies}

Our results are in accordance with a recent model developed in the $\mathrm{UK}^{(28,32)}$, where a $13 \%$ CVD mortality reduction by 2030 was reported after reducing the consumption of processed and ultra-processed foods. Although the scenarios modelled in that study are not directly comparable, a possible explanation for the higher mortality reductions reported in our study could be the higher content of salt and added sugar of the Brazilian traditional diet compared with the UK. Salt intake in Brazil is about $12 \mathrm{~g} / \mathrm{d}$ while this is approximately $8 \mathrm{~g} / \mathrm{d}$ in the $\mathrm{UK}^{(39,40)}$. In addition, Brazil has been historically the major global producer of sugar.

Although no other studies seem to quantify the effect of UPF consumption on CVD mortality, there are some studies looking directly at the effect of saturated fat, trans-fat and salt on CHD mortality only ${ }^{(24-26,40)}$.

A modelling study in nine European countries evaluated decreases in salt and saturated fat consumption ${ }^{(41)}$. It reported CHD mortality gains of between 5 and $16 \%$ by 
Table 2 Estimated CVD, CHD and stroke deaths prevented or postponed (DPP) by 2030 by the achievement of modest, ideal and optimistic scenarios (reducing intakes of saturated fat, trans-fat, salt and added sugar from ultra-processed foods and processed culinary ingredients) in specific food policy options, by sex, in Brazil

\begin{tabular}{|c|c|c|c|c|c|c|}
\hline & \multicolumn{4}{|c|}{$\operatorname{DPP}(n)$} & \multicolumn{2}{|c|}{ DPP (\%) } \\
\hline & Men & $95 \% \mathrm{Cl}$ & Women & $95 \% \mathrm{Cl}$ & Men + women & $95 \% \mathrm{Cl}$ \\
\hline \multicolumn{7}{|c|}{ Scenario A (modest) } \\
\hline CVD & 11670 & 9130,14690 & 9430 & 7090,12360 & $5 \cdot 5$ & $4.5,6.5$ \\
\hline CHD & 5570 & 4000,7330 & 3730 & 2590,5120 & 4.8 & $4 \cdot 0,6 \cdot 0$ \\
\hline Stroke & 6100 & 4410,8170 & 5700 & 3970,7950 & $6 \cdot 0$ & $4 \cdot 5,6 \cdot 5$ \\
\hline \multicolumn{7}{|c|}{ Scenario B (ideal) } \\
\hline CVD & 24180 & 19400,29160 & 20010 & 15408,24770 & $11 \cdot 0$ & $9 \cdot 6,13 \cdot 0$ \\
\hline $\mathrm{CHD}$ & 11460 & 8360,14670 & 7880 & 5470,10320 & $10 \cdot 0$ & $8 \cdot 0,12 \cdot 0$ \\
\hline Stroke & 12720 & 9370,16370 & 12130 & 8550,15970 & $12 \cdot 6$ & $10 \cdot 0,15 \cdot 0$ \\
\hline \multicolumn{7}{|c|}{ Scenario C (optimistic) } \\
\hline CVD & 59510 & 36400,85630 & 51630 & 31690,74780 & $29 \cdot 0$ & $18 \cdot 0,41 \cdot 0$ \\
\hline CHD & 27440 & 12220,44080 & 20300 & 9140,32830 & $25 \cdot 0$ & $11.0,40 \cdot 0$ \\
\hline Stroke & 32070 & 15510,50290 & 31330 & 15160,49560 & $32 \cdot 0$ & $16 \cdot 0,50 \cdot 0$ \\
\hline
\end{tabular}

2020. The study additionally modelled decreases in added sugar and trans-fats and reported CHD mortality gains of between 5 and $25 \%$ by $2030^{(41)}$.

A study looking at 50 and $100 \%$ reduction of trans-fats in England and Wales reported a mortality reduction of 1.3 and $2 \cdot 5 \%$, respectively, by $2020^{(42)}$.

\section{Strengths and limitations}

To our knowledge, the present study is the first model to estimate the impact of reducing ultra-processed foods and processed culinary ingredients from the Brazilian diet on CVD mortality.

The NOVA food classification used in the study has been widely applied to other countries ${ }^{(32)}$ and is now recognised as a valid tool in reports from the $\mathrm{FAO}^{(43)}$ and the Pan American Health Organization ${ }^{(44)}$. The effect sizes quantifying the relative change in CVD mortality that would result from a one-unit change in nutrient level were obtained from comprehensive systematic reviews and meta-analyses. We also considered that changes in nutrient values might not be independent and additive, and we therefore explored potential cumulative effects. We incorporate the uncertainty associated to the measurement of nutrient values by conducting a full sensitivity analysis.

On the other hand, the study also has some limitations. The Brazilian HBS was used to quantify saturated fat, trans-fat, salt and added sugar. The HBS has data on foods purchased rather than foods consumed and it does not take in account foods purchased outside the home. However, such data are well accepted for estimating consumption in populations, with many studies using it for this purpose in Brazil ${ }^{(9,17,45)}$, and the HSB has shown reasonable agreement between purchased and home consumption of $\mathrm{UPF}^{(46)}$. Furthermore, for trans-fat, a representative sub-sample of 34003 individuals was used $^{(35)}$. This sub-sample contains only $25 \%$ of the households in the HBS and does not include detailed information on processed culinary ingredients (G2) which were used in this modelling exercise to estimate intakes of sugar and salt. Because of these limitations, it was decided to use the purchased food data reported by the HSB.

Claro et $a l .{ }^{(47)}$ report that approximately $28 \%$ of total expenditure on food happens away from home. Moreover, the consumption of ready-to-consume products tends to be higher outside home ${ }^{(48)}$; therefore, our estimates of consumption of UPF might underestimate the consumption of UPF in Brazil.

We assumed no 'lag time' between dietary risk factor change and mortality reduction. Indeed, lag times for CVD are surprisingly short and considerable declines in mortality can occur rapidly after individual or population-wide changes in diet ${ }^{(49)}$. The model does not track future risk factor trends, and this might result in over- or underestimation of the potential reduction. However, given the size of the reductions, the model seems to offer conservative estimates of potential future gains.

We could not estimate the age-specific nutrient content from the HSB, as these data were not available in the survey. Therefore, we used the age pattern of nutrient consumption observed in the UK, applied to the Brazilian population. This may lead to biased estimates of nutrient content in the Brazil diet since the UK consumes more than double the amount of UPF.

We also assumed that CVD mortality will keep constant until 2030, which is a common assumption in modelling studies $^{(50)}$. However, important reductions in the mortality trends have been observed and projected for industrialized countries ${ }^{(50-52)}$. Therefore, it would not be unreasonable to assume that also Brazil might have some reduction in mortality trends into the future.

Finally, we did not take into account that an intake reduction of UPF might also drive a higher consumption of other less processed foods such as cheese and breads (classified in G3), since they might be perceived as healthier options in comparison to their ultra-processed counterparts. However, these foods are still high in salt, added sugar and saturated fat, and an increased intake of those could reduce or cancel the health benefits of a reduction of UPF. 


\section{Public bealth implications}

Unhealthy aspects of traditional foods in Brazil, including their high levels of salt and sugar, and the increasing number of processed and ultra-processed foods penetrating the Brazilian diet demand public actions to mitigate their negative effects.

In our study, the contribution of added sugar in percentage of total energy was approximately $16 \%$. Approximately $50 \%$ of this energy percentage comes from G2 (oils, fats, salt and sugar) and about 18\% comes from G4 (UPF). Brazil has a high intake of sugar, exceeding the standards recommended for international use ${ }^{(53)}$. Fortunately, the consumption of refined sugars and other caloric sweeteners, which correspond to $75 \%$ of the energy consumed from added sugars, has been decreasing in the last decades ${ }^{(54)}$. However, the consumption remains high. Moreover, the proportion of added sugars from processed and ultra-processed foods (the remaining 25\% of energy from added sugars) has increased significantly, doubling between 1988 and $2003^{(54)}$.

This high consumption may lead to increase in total energy intake related to overweight and obesity and increase of non-communicable diseases ${ }^{(20,21)}$. According to the $\mathrm{WHO}$, the recommendation is to reduce the intake of added sugar to less than $10 \%$ of total energy intake ${ }^{(55)}$.

Recent modelling studies show that a tax on sugarsweetened beverages affects consumption in the whole population and may lead to a reduction in overweight and obesity $^{(41)}$. According to the Instituto Nacional de Salud Pública in Mexico, a $10 \%$ tax on some sugar-sweetened beverages showed approximately a $10 \%$ decline in purchases of those beverages. Results also showed a $7 \%$ increase in purchase of untaxed beverages and roughly a $13 \%$ increase in plain water purchases (preliminary results) ${ }^{(56)}$.

Another important issue is the amount of salt in the Brazilian diet. In our results, the mean of salt purchased is about $10 \mathrm{~g} / \mathrm{d}$. The weighted average of salt in G2 was $7 \cdot 75 \mathrm{~g} / \mathrm{d}$ and in $\mathrm{G} 4$ was $2 \cdot 26 \mathrm{~g} / \mathrm{d}$. In previous studies in Brazil, the quantity of salt was about $12 \mathrm{~g} /$ capita per $\mathrm{d}$, more than the recommended daily intake level ${ }^{(40,57,58)}$. There was a slight decrease from 76.2 to $74.4 \%$ in the contribution of salt and salt-based condiments, however an increase of processed foods with added salt (15.8 to $18.9 \%$ ) by households, in the two last surveys ${ }^{(57,58)}$.

A US modelling study suggested that reducing dietary salt by $3 \mathrm{~g} / \mathrm{d}$ could lead to a reduction in cases of CHD, stroke and myocardial infarction ${ }^{(29)}$. Other studies have shown that interventions to reduce dietary salt intake are linked with decreases in health-care expenditure and reductions in the burden of $\mathrm{CVD}^{(26,59)}$.

Some models have evaluated policies to reduce salt consumption through health promotion campaigns, labelling of food packaging and mandatory reformulation of salt content in processed food; Mason et al. ${ }^{(60)}$ evaluated the above policies in four Mediterranean countries and found them to be cost saving due to the reduction in CHD numbers. In England, the largest estimated savings came from mandatory reformulation, implementing legislation to reduce salt in processed foods ${ }^{(26)}$. In Brazil, the Brazilian Strategic Action Plan to Combat Chronic Noncommunicable Diseases (2011-2022) aims to reduce salt consumption from $12 \mathrm{~g} / \mathrm{d}$ (in 2010) to $5 \mathrm{~g} / \mathrm{d}$ (in 2022). Actions to achieve the goal are educational measures to reduce salt and salty condiments added at home; agreements with the food industry to reduce the salt in its products; and restrictions on the marketing of $\mathrm{UPF}^{(61)}$.

In Argentina, two cost-effective population-based interventions are decreasing salt levels in bread and mass education campaigns ${ }^{(62)}$. Cappuccio et al. ${ }^{(63)}$ stressed that in low- and middle-income countries, with very limited budgets, policies could be related to communication, reformulation, monitoring and regulation.

In a recent systematic review of salt reduction around the world, Trieu et al. ${ }^{(64)}$ found that national salt reduction strategies are implemented in countries at all income levels (income level by the World Bank) and the strategies adopted are food reformulation, consumer education, front-of-package labelling and interventions in public settings such as schools, workplaces, public hospitals and other public institutions.

Furthermore, the increase of UPF in the Brazilian diet will inevitably bring an increase in saturated fats and trans-fats. Reduction of saturated fats has been a traditional strategy for prevention of $\mathrm{CHD}^{(24)}$ and certainly the proposed scenarios in the present study could contribute to such reduction. However, most of the saturated fats in the Brazilian diet come from foods in G3 (i.e. processed foods, see Fig. 1), meaning that this group cannot be ignored and needs considerable policy focus. Mozaffarian et al. showed in a meta-analysis that increasing the consumption of PUFA as a replacement for saturated fat could reduce CHD events by $19 \%^{(24)}$.

Trans-fat has a substantial effect on CHD risk as it increases harmful LDL cholesterol ${ }^{(65-67)}$. In 2003, the WHO set the target of reducing trans-fats consumption to $0.8 \%$ of daily energy intake after the overwhelming evidence of its harms ${ }^{(40)}$. In Brazil, the consumption of trans-fats is just above that target (an average consumption of $1 \cdot 1 \%$, see online supplementary material). Our study suggests that by reducing the consumption of UPF by more than $25 \%$ will help Brazil to keep its levels of trans-fats consumption below the WHO target.

\section{Conclusion}

The current study shows there is potential for substantially reducing the CVD burden through overall improvements of the Brazilian diet. Reducing consumption of saturated fat, trans-fat, salt and added sugar in processed and ultraprocessed foods could result in a 6-29\% decrease in 
deaths from CVD. This requires reducing the penetration of ultra-processed products by means of regulatory policies, as well as improving access to and promotion of fresh and minimally processed foods that are still part of Brazil's traditional diet.

\section{Acknowledgements}

Financial support: This work was supported by the National Council of Technological and Scientific Development (Conselho Nacional de Desenvolvimento Científico e Tecnológico (CNPq); grant number 245501/2012-6). CNPq had no role in the design, analysis or writing of this article. Conflict of interest: None. Authorship: The authors contributed as follows. Formulating the research question: P.V.L.M., S.C., M.O.F. and M.G.C. Designing the study: P.L.V.M., S.C., M.O.F. and M.G.-C. Analysing the data: P.V.L.M., M.O.F., M.G.-C., A.P.B.M., L.G.B. and J.-C.M. Writing the article: P.V.L.M., L.H., A.P.B.M., L.G.B., J.-C.M., M.G.-C., H.B., S.C. and M.O.F. Ethics of human subject participation: Not applicable.

\section{Supplementary material}

To view supplementary material for this article, please visit https://doi.org/10.1017/S1368980017002063

\section{References}

1. Lozano R, Naghavi M, Foreman K et al. (2012) Global and regional mortality from 235 causes of death for 20 age groups in 1990 and 2010: a systematic analysis for the Global Burden of Disease Study 2010. Lancet 380, 2095-2128.

2. Vos T, Barber RM, Bell B et al. (2015) Global, regional, and national incidence, prevalence, and years lived with disability for 301 acute and chronic diseases and injuries in 188 countries, 1990-2013: a systematic analysis for the Global Burden of Disease Study 2013. Lancet 386, 743-800.

3. Lim SS, Vos T, Flaxman AD et al. (2012) A comparative risk assessment of burden of disease and injury attributable to 67 risk factors and risk factor clusters in 21 regions, 1990-2010: a systematic analysis for the Global Burden of Disease Study 2010. Lancet 380, 2224-2260.

4. Poti JM, Mendez MA, Ng SW et al. (2015) Is the degree of food processing and convenience linked with the nutritional quality of foods purchased by US households? Am J Clin Nutr 101, 1251-1262.

5. Steele EM, Baraldi LG, Louzada MLC et al. (2016) Ultraprocessed foods and added sugars in the US diet: evidence from a nationally representative cross-sectional study. BMJ Open 6, e009892.

6. Adams J \& White M (2015) Characterisation of UK diets according to degree of food processing and associations with socio-demographics and obesity: cross-sectional analysis of UK National Diet and Nutrition Survey (2008-12). Int J Behav Nutr Phys Act 12, 160.

7. Louzada MLC, Martins APB, Canella DS et al. (2015) Ultraprocessed foods and the nutritional dietary profile in Brazil. Rev Saude Publica 49, 38.
8. Louzada MLC, Martins APB, Canella DS et al. (2015) Impact of ultra-processed foods on micronutrient content in the Brazilian diet. Rev Saude Publica 49, 45.

9. Crovetto MM, Uauy R, Martins AP et al. (2014) Household availability of ready-to-consume food and drink products in Chile: impact on nutritional quality of the diet. Rev Med Chil 142, 850-858.

10. Moubarac J-C, Martins APB, Claro RM et al. (2013) Consumption of ultra-processed foods and likely impact on human health. Evidence from Canada. Public Health Nutr 16, 2240-2248.

11. Monteiro CA, Moubarac J-C, Cannon G et al. (2013) Ultraprocessed products are becoming dominant in the global food system. Obes Rev 14, 21-28.

12. Moubarac J-C, Claro RM, Baraldi LG et al. (2013) International differences in cost and consumption of readyto-consume food and drink products: United Kingdom and Brazil, 2008-2009. Glob Public Health 8, 845-856.

13. Monteiro CA \& Cannon G (2012) The impact of transnational 'Big Food' companies on the South: a view from Brazil. PLoS Med 9, e1001252.

14. Martins AP, Levy RB, Claro RM et al. (2013) Increased contribution of ultra-processed food products in the Brazilian diet (1987-2009). Rev Saude Publica 47, 656-665.

15. Monteiro CA, Conde WL \& Popkin BM (2007) Incomespecific trends in obesity in Brazil: 1975-2003. Am J Public Health 97, 1808-1812.

16. Monteiro CA, D'A Benicio MH, Conde WL et al. (2000) Shifting obesity trends in Brazil. Eur J Clin Nutr 54, 342-346.

17. Canella DS, Levy RB, Martins APB et al. (2014) Ultraprocessed food products and obesity in Brazilian households (2008-2009). PLoS One 9, e92752.

18. Yang Q, Zhang Z, Gregg EW et al. (2014) Added sugar intake and cardiovascular diseases mortality among US adults. JAMA Intern Med 174, 516-524.

19. Welsh JA, Sharma A, Argeseanu S et al. (2011) Consumption of added sugars and cardiometabolic risk indicators among US adolescents. Circulation 123, 249-257.

20. de Koning L, Malik VS, Kellogg MD et al. (2012) Sweetened beverage consumption, incident coronary heart disease and biomarkers of risk in Men. Circulation 125, 1735-1741.

21. Fung TT, Malik V, Rexrode KM et al. (2009) Sweetened beverage consumption and risk of coronary heart disease in women. Am J Clin Nutr 89, 1037-1042.

22. Nagata C, Takatsuka N, Shimizu N et al. (2004) Sodium intake and risk of death from stroke in Japanese men and women. Stroke 35, 1543-1547.

23. Strazzullo P, D'Elia L, Kandala N-B et al. (2009) Salt intake, stroke, and cardiovascular disease: meta-analysis of prospective studies. BMJ 339, b4567.

24. Mozaffarian D, Micha R \& Wallace S (2010) Effects on coronary heart disease of increasing polyunsaturated fat in place of saturated fat: a systematic review and meta-analysis of randomized controlled trials. PLoS Med 7, e1000252.

25. Oh K, Hu FB, Manson JE et al. (2005) Dietary fat intake and risk of coronary heart disease in women: 20 years of followup of the Nurses' Health Study. Am J Epidemiol 161, 672-679.

26. Collins M, Mason H, O'Flaherty M et al. (2014) An economic evaluation of salt reduction policies to reduce coronary heart disease in England: a policy modeling study. Value Health 17, 517-524.

27. O'Flaherty M, Flores-Mateo G, Nnoaham K et al. (2012) Potential cardiovascular mortality reductions with stricter food policies in the United Kingdom of Great Britain and Northern Ireland. Bull World Health Organ 90, 522-531.

28. Moreira PVL, Baraldi LG, Moubarac JC et al. (2014) OP10 Comparing UK policies to reduce the consumption of 
ultra-processed foods: cardiovascular modelling study. $J$ Epidemiol Community Health 68, A8.

29. Bibbins-Domingo K, Chertow GM, Coxson PG et al. (2010) Projected effect of dietary salt reductions on future cardiovascular disease. $N$ Engl J Med 362, 590-599.

30. Brazilian Institute of Geography and Statistics (2010) Pesquisa de Orçamentos Familiares 2008-2009. Aquisição Alimentar Domiciliar per capita Brasil e Grandes Regiões. Rio de Janeiro: IBGE.

31. Monteiro CA, Cannon G, Levy R et al. (2016) NOVA. The star shines bright. World Nutr 7, 28-38.

32. Moreira PVL, Baraldi LG, Moubarac J-C et al. (2015) Comparing different policy scenarios to reduce the consumption of ultra-processed foods in UK: impact on cardiovascular disease mortality using a modelling approach. PLoS One 10, e0118353.

33. Center of Food Studies, State University of Campinas (2011) Tabela Brasileira de Composição de Alimentos TACO (Brazilian Food Composition Table), 4th ed. Campinas: NEPA/UEC

34. US Department of Agriculture (2002) USDA National Nutrient Database for Standard Reference, Release 15. Beltsville, MD: USDA.

35. Brazilian Institute of Geography and Statistics (2011) Pesquisa de Orçamentos Familiares 2008-2009: Análise do Consumo Alimentar Pessoal no Brasil. Rio de Janeiro: IBGE.

36. Pereira RA, Duffey KJ, Sichieri R et al. (2014) Sources of excessive saturated fat, trans fat and sugar consumption in Brazil: an analysis of the first Brazilian Nationwide Individual Dietary Survey. Public Health Nutr 17, 113-121.

37. O'Keeffe C, Kabir Z, O'Flaherty M et al. (2013) Modelling the impact of specific food policy options on coronary heart disease and stroke deaths in Ireland. BMJ Open 3, e002837.

38. Lewington S, Clarke R, Qizilbash N et al. (2002) Age-specific relevance of usual blood pressure to vascular mortality: a meta-analysis of individual data for one million adults in 61 prospective studies. Lancet 360, 1903-1913.

39. Brinsden HC, He FJ, Jenner KH et al. (2013) Surveys of the salt content in UK bread: progress made and further reductions possible. BMJ Open 3, e002936.

40. World Health Organization (2003) Diet, Nutrition and the Prevention of Chronic Diseases. Joint WHO/FAO Expert Consultation. WHO Technical Report Series no. 916. Geneva: WHO.

41. Andersen K, Aspelund T, Bandosz P et al. (2014) CHD mortality projections to 2020, comparing different policy scenarios. EuroHeart II Work Package 6. https://www. escardio.org/static_file/Escardio/EU-Affairs/chd-mortality.pdf (accessed August 2017).

42. Pearson-Stuttard J, Hooton W, Critchley J et al. (2016) Costeffectiveness analysis of eliminating industrial and all trans fats in England and Wales: modelling study. J Public Health (Oxf) (Epublication ahead of print version).

43. Food and Agriculture Organization of the United Nations (2015) Guidelines on the Collection of Information on Food Processing through Food Consumption Surveys. Rome: FAO.

44. Pan American Health Organization (2015) Ultra-Processed Food and Drink Products in Latin America: Trends, Impact on Obesity, Policy Implications. Washington, DC: PAHO.

45. Monteiro CA, Levy RB, Claro RM et al. (2011) Increasing consumption of ultra-processed foods and likely impact on human health: evidence from Brazil. Public Health Nutr 14, $5-13$.

46. Louzada MLC (2015) Nutrition and Health: the role of food ultraprocessing. PhD Thesis, University of São Paulo.

47. Claro RM, Baraldi LG, Martins APB et al. (2014) Trends in spending on eating away from home in Brazil, 2002-2003 to 2008-2009. Cad Saude Publica 30, 1418-1426.
48. Bezerra IN, Souza AM, Pereira RA et al. (2013) Contribution of foods consumed away from home to energy intake in Brazilian urban areas: the 2008-9 Nationwide Dietary Survey. Br J Nutr 109, 1276-1283.

49. Capewell S \& O'Flaherty M (2011) Rapid mortality falls after risk-factor changes in populations. Lancet $\mathbf{3 7 8}$, 752-753.

50. Guzman Castillo M, Gillespie DOS, Allen K et al. (2014) Future declines of coronary heart disease mortality in England and Wales could counter the burden of population ageing. PLoS One 9, e99482.

51. Huovinen E, Härkänen T, Martelin T et al. (2006) Predicting coronary heart disease mortality - assessing uncertainties in population forecasts and death probabilities by using Bayesian inference. Int J Epidemiol 35, 1246-1252.

52. Pearson-Stuttard J, Guzman-Castillo M, Penalvo J et al. (2016) Modelling future cardiovascular disease mortality in the United States: national trends and racial and ethnic disparities. Circulation 133, 967-978.

53. US Department of Agriculture (2015) Scientific Report of the 2015 Dietary Guidelines Advisory Committee. Beltsville, MD: USDA.

54. Levy RB, Claro RM, Bandoni DH et al. (2012) Availability of added sugars in Brazil: distribution, food sources and time trends. Rev Bras Epidemiol 15, 3-12.

55. World Health Organization (2015) Guideline: Sugars Intake for Adults and Children. Geneva: WHO.

56. Instituto Nacional de Salud Pública (2015) Resultados preliminares sobre los efectos del impuesto de un peso a bebidas azucaradas en México. http://www.insp.mx/ epppo/blog/preliminares-bebidas-azucaradas.html (accessed October 2015).

57. Sarno F, Claro RM, Levy RB et al. (2009) Estimated sodium intake for the Brazilian population, 2002-2003. Rev Saude Publica 43, 219-225.

58. Sarno F, Claro RM, Levy RB et al. (2013) Estimated sodium intake for the Brazilian population, 2008-2009. Rev Saude Publica 47, 571-578.

59. Smith-Spangler CM, Juusola JL, Enns EA et al. (2010) Population strategies to decrease sodium intake and the burden of cardiovascular disease a cost-effectiveness analysis. Ann Intern Med 152, 481-487.

60. Mason H, Shoaibi A, Ghandour R et al. (2014) A Cost effectiveness analysis of salt reduction policies to reduce coronary heart disease in four eastern Mediterranean countries. PLoS One 9, e84445.

61. Malta DC \& Silva JB da Jr (2013) O plano de ações estratégicas para o enfrentamento das doenças crônicas não transmissíveis no Brasil e a definição das metas globais para o enfrentamento dessas doenças até 2025: uma revisão. Epidemiol Serv Saude 22, 151-164.

62. Rubinstein A, García Martí S, Souto A et al. (2009) Generalized cost-effectiveness analysis of a package of interventions to reduce cardiovascular disease in Buenos Aires, Argentina. Cost Eff Resour Alloc 7, 1-10.

63. Cappuccio FP, Capewell S, Lincoln P et al. (2011) Policy options to reduce population salt intake. BMJ 343, d4995.

64. Trieu K, Neal B, Hawkes C et al. (2015) Salt reduction initiatives around the world - a systematic review of progress towards the global target. PLoS One 10, e0130247.

65. Mozaffarian D, Katan MB, Ascheria A et al. (2006) Trans fatty acids and cardiovascular disease. $N$ Engl J Med 354, $1601-1613$.

66. Mozaffarian D, Aro A \& Willet WC (2009) Health effects of trans-fatty acids: experimental and observational evidence. Eur J Clin Nutr 63, Suppl. 2, S5-S21.

67. Willett WC (2012) Dietary fats and coronary heart disease. J Intern Med 272, 13-24. 